occurs at a time when more and more elderly patients are entering the health care system. The study suggests that increased screening and feedback will improve detection of mental illness in the aged population.

"Multihospital systems: Perspectives and trends" offers predictions about changes in the health care industry over the next decade. Over 650 professionals were surveyed by the American Hospital Association/Arthur Anderson and Co. for the report.

The responders agreed that the cost of caring for the medically indigent will almost double by 1995 . Medicare will change significantly, with benefits being determined by the income level of the beneficiary. The government will move away from the prospective pricing system and shift care to prepaid systems such as HMOs and PPOs.

The majority felt that a hospital's tax-exempt status should be based on providing a minimum amount of indigent care. Participants from investor-owned hospitals, however, felt this level should be higher than did respondents from not-for-profit systems.

\section{advertisers' index}

Abbott Laboratories

Hytrin, 69

Beecham Laboratories

Fastin, 28-30

Ciba Pharmaceuticals

Estraderm, 17-20

Electro-Med Health Industries, Inc., 74

Fisons Corporation

Nasalcrom, 85

Flint Osteopathic Hospital, 62

Glenwood, Inc.

Calphosan, 2

Gerber Products Company, 26

Humana Medfirst, 71

Key Pharmaceuticals Nitro-Dur II, 46-48

Lederle Laboratories Asendin, 60, 61

Lemmon Company Adipex-P, 41, 42

Lever Brothers, Inc. Dove Bar, Cover 3

Lilly \& Company, Eli Ceclor, 4

Marion Laboratories Cardizem, 75-78

McNeil Pharmaceuticals Tolectin, 43, 44

Merrell Dow Pharmaceutical, Inc.

Lorelco, 63-66

Seldane, 87-90

Merck Sharp \& Dohme

Vaseretic, 31-35

Muro Pharmaceutical Inc.

Bromfed, 39, 40

Pfizer Laboratories

Feldene, 53, 54

Procardia, 10-12

Roche Laboratories Medical Director's Page, 3

Roche Products Inc.

Valium, 56, 57

Ross Laboratories

Pediazole, 58, 59

Similac, 49

Sandoz Pharmaceuticals

Tavist-2, 15, 16

Schein Inc., Henry, 23

Schering Laboratories

Normodyne, 6-8

Smith Kline \& French Laboratories

Tagamet, Cover 4

Squibb \& Sons, Inc., E.R.

Capozide, 99-102

Stuart Pharmaceuticals

Tenoretic, 118-122

Syntex Laboratories, Inc.

Anaprox, 51, 52

Upjohn Company

Medrol, 73

Micronase, $36-38$

Motrin, 25

Xanax, Cover 2-2 


\section{The New Look of \\ Medrol Dosepak Unit of Use 4 mg methylprednisolone tablets, USP}

The explicit printed dosage instructions that accompany each Dosepak make it easy for the patient to understand and follow the dosage regimen.

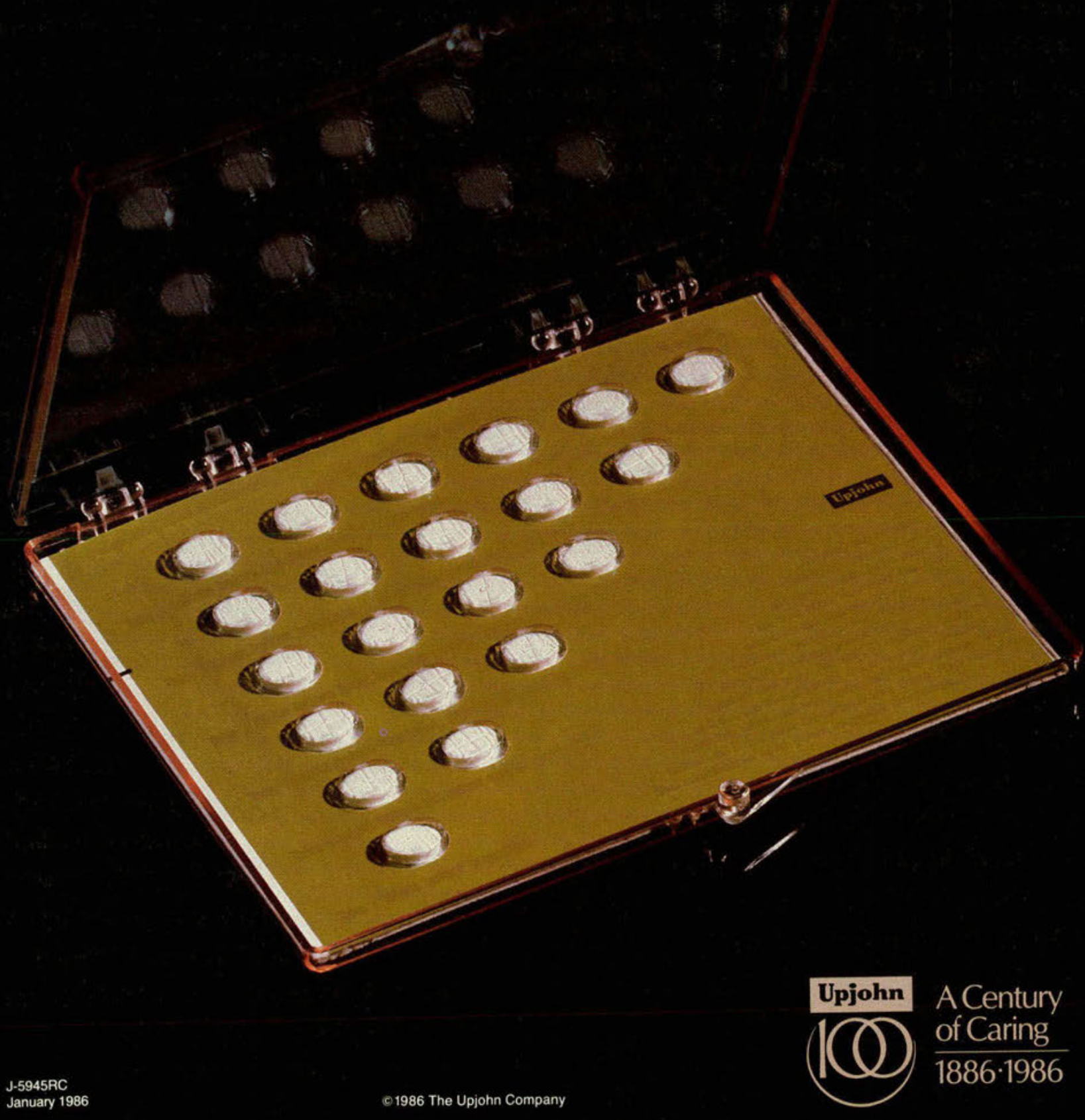




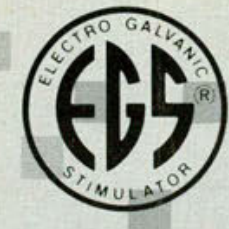

HIGH VOLTAGE

PULSED GALVANIC

STIMULATOR

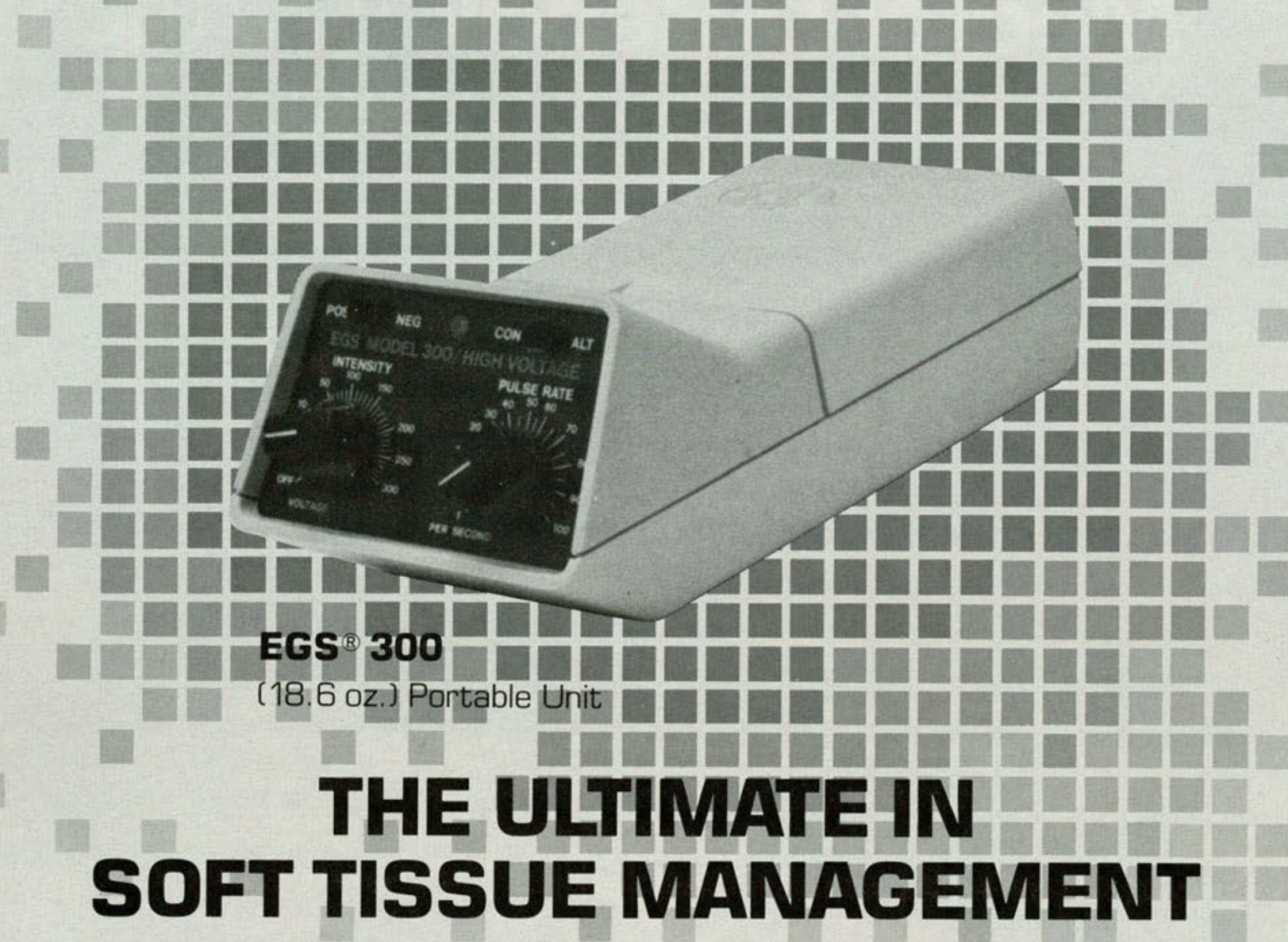

- Relieve spasticity and spasms (i.e. TMJ dysfunction)

- Increase local blood flow

- Delay atrophy from disuse in partially denervated muscle

- Re-educate muscle as in regaining joint control

- Stimulate calf post-operatively to prevent phlebothrombosis

- Relieve pain (EGS 300 only) when applied as a TENS

- Reduction of edema

- Totally safe

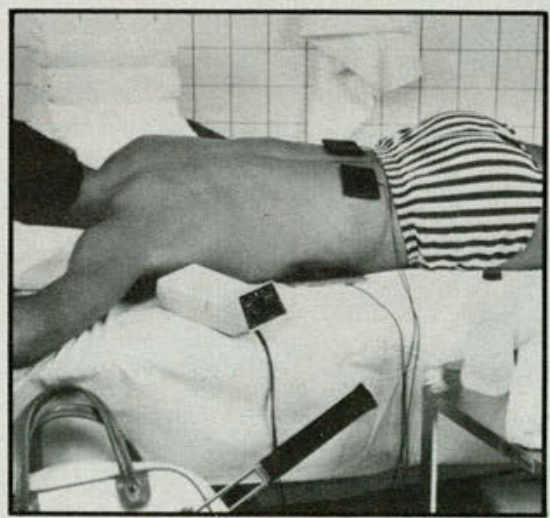

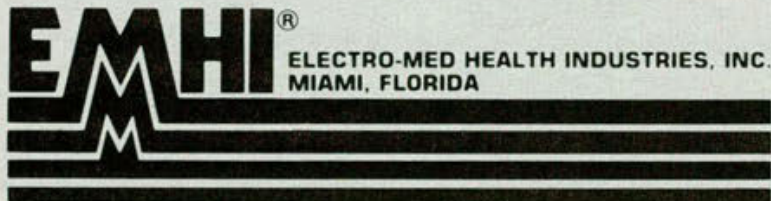

'Manufacturers of Electro-Medical/Dental Equipment

6240 N.E. 4th Court · Miami, Florida 33138-6106 Phone: (305) 756-6013, Telex: 152303 EMHI UT

CAUTION: FEDERAL LAW RESTRICTS THIS DEVICE TO SALE BY OR ON THE ORDER OF A LICENSED PRACTITIONER
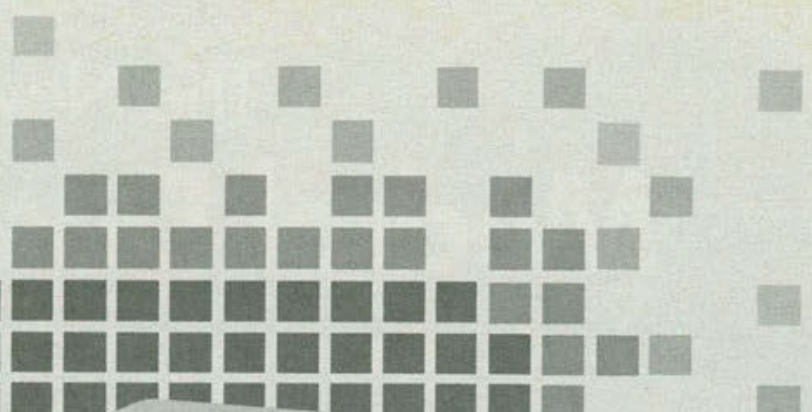


\section{GHE YOUR ANGIMA PAIIENTS

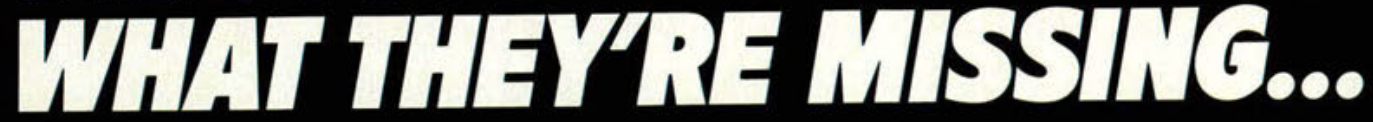

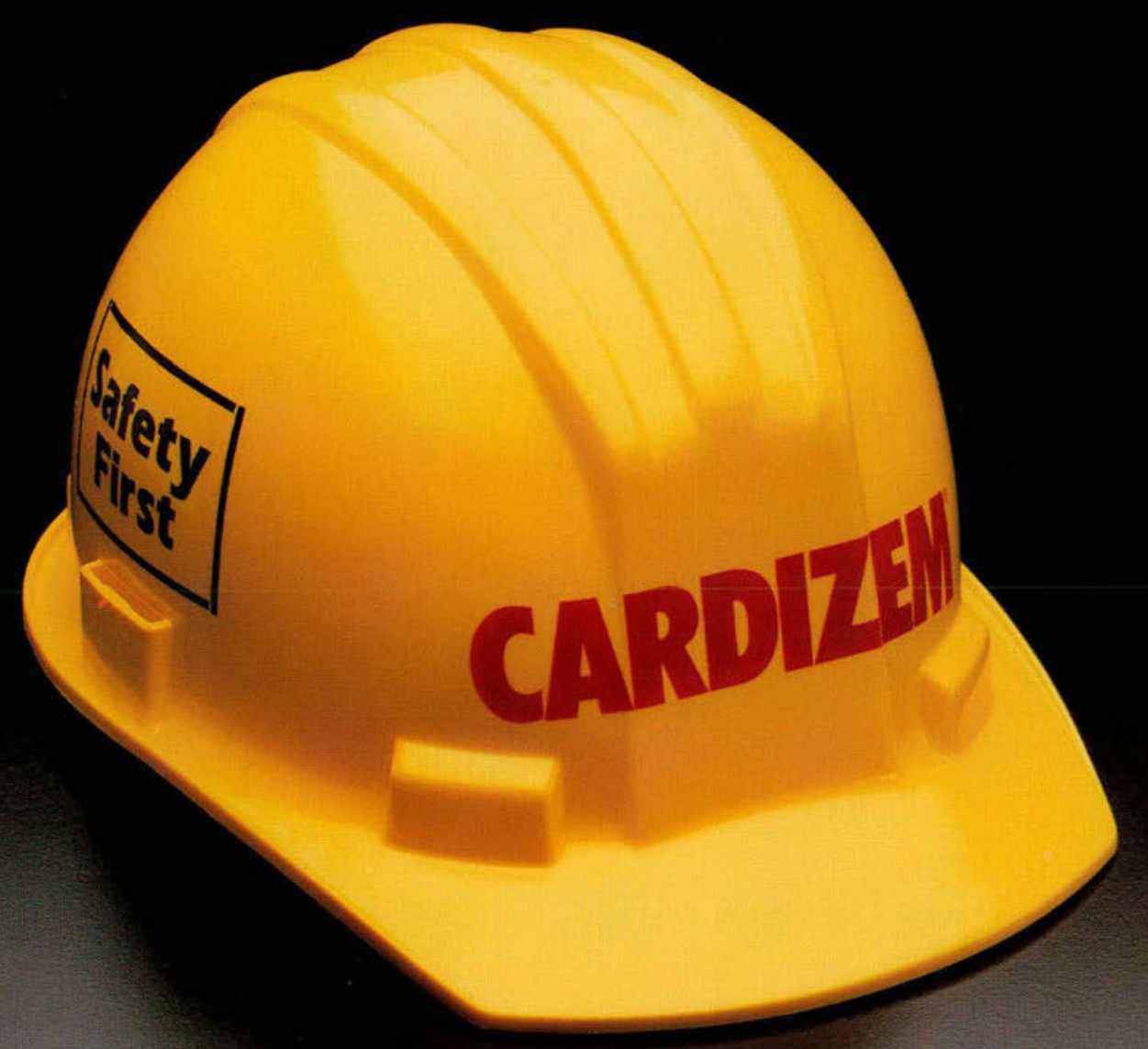

CARDHAT dilitiazem HCl/Marion 

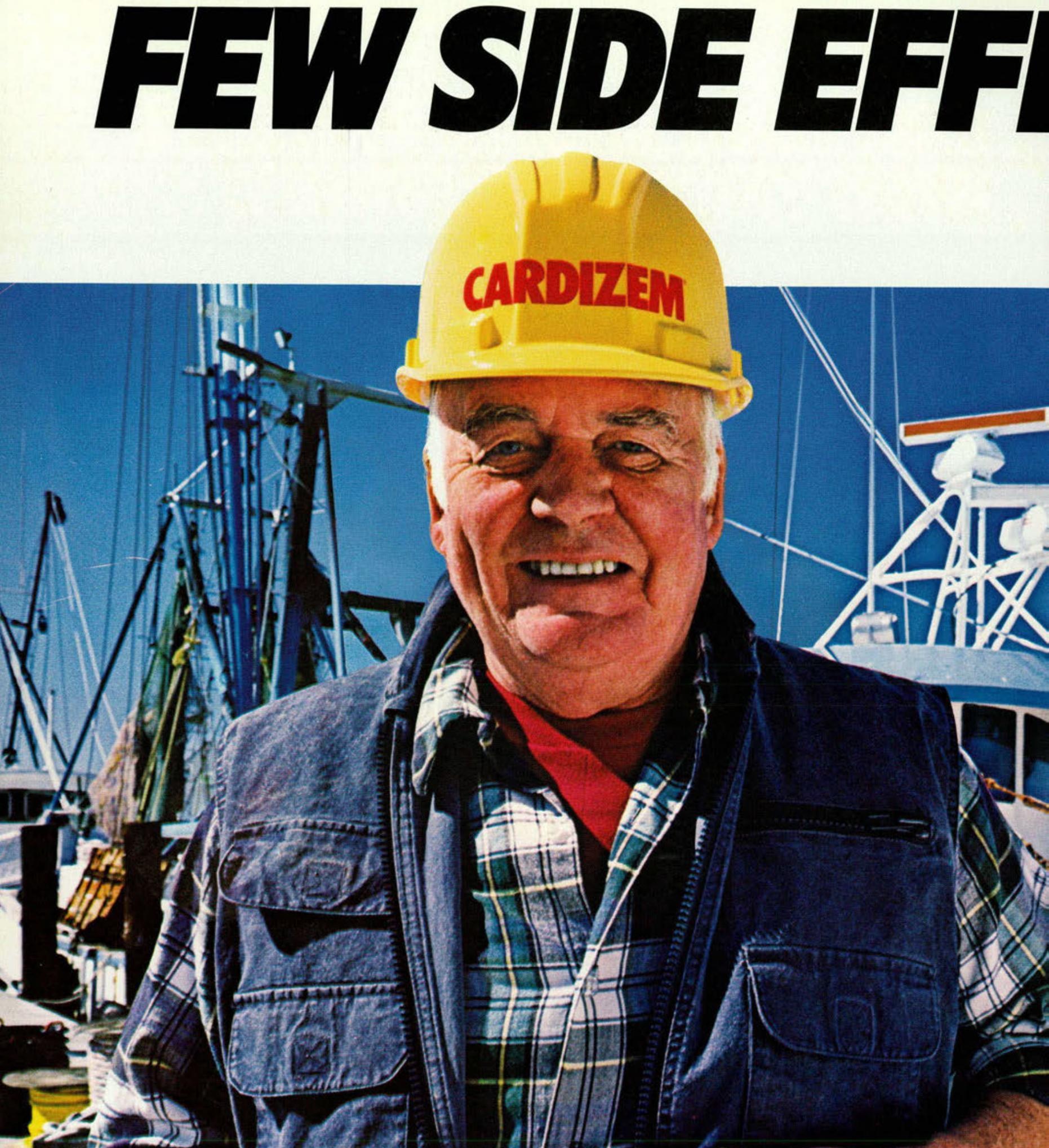


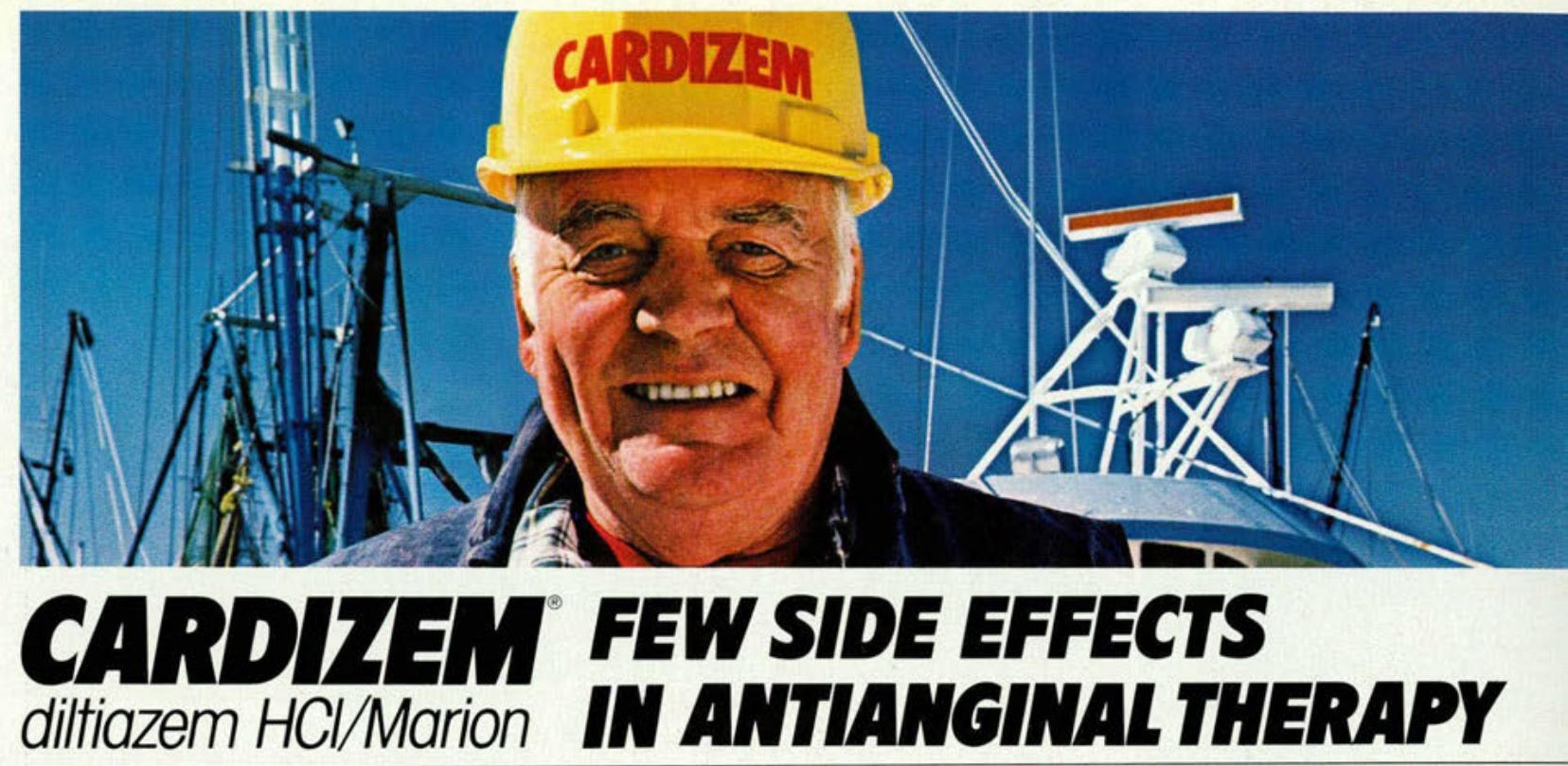

\section{$60 \mathrm{mg}$ tid or qid}

Brief Summary

Professional Use Information

\section{CARDIZEM"}

(dilfiazem HCl) $30 \mathrm{mg}$ and $60 \mathrm{mg}$ Tablets

\section{CONTRAINDICATIONS}

CARDIZEM is contraindicated in (1) patients with sick sinus syndrome except in the presence of a functioning ventricular pocemaker, (2) patients with second-or third-degree AV block except in the presence of a functioning ventricular pacemaker, and (3) patients with hypotension (less than $90 \mathrm{~mm} \mathrm{Hg}$ systolic).

\section{WARNINGS}

1. Cardiac Conduction. CARDIZEM prolongs AV node refractory periods without significantly prolonging sinus node recovery time, except in potients with sick sinus syndrome. This effect may rarely result in abnormally slow heart rates (particularly in potients with sick sinus syndrome) or second- or third-degree AV block (six of 1,243 patients for $0.48 \%$ ) Concomitant use of diltiozem with beta-blockers or digitalis may result in additive effects on cardiac conduction. A patient with Prinzmetal's angina developed periods of asystole (2 to 5 seconds) after a single dose of $60 \mathrm{mg}$ of dilitiazem.

2. Congestive Heart Foilure. Although dilfiazem has a negative inotropic effect in isolated animal tissue preparations, hemodynamic studies in humans with normal ventricular function have not shown a reduction in cardiac index nor consistent negative effects on contractility ( $d p / d t)$.

Experience with the use of CARDIZEM

alone or in combination with beto-blockers in patients with impaired ventricular function is very limited. Caution should be exercised when using the drug in such patients.

3. Hypotension. Decreases in blood pressure asso ciated with CARDIZEM therapy may occosionally result in symptomatic hypotension.

4. Acute Hepatic Injury. In rare instances, significant elevations in enzymes such as alkaline phosphatose, CPK, LDH, SGOT SGPT, and other symptoms consistent with acute hepatic injury have been noted. These reactions have been reversible upon discontinuation of drug therapy. The relationship to CARDIZEM is uncertain in most cases, but probable in some. (See PRECAUTIONS.)

\section{PRECAUTIONS}

General. CARDIZEM (diltiazem hydrochloride) is extensively metabolized by the liver and excreted by the kidneys and in bile. As with any new drug given over prolonged periods, laboratory parameters should be monitored at regular intervals. The drug should be used with caution in patients with impaired renal or hepatic function. In subacute and chronic dog and rat studies designed to produce toxicity, high doses of diltiazem were associated with hepatic damage. In special subacute hepatic studies, oral doses of $125 \mathrm{mg} / \mathrm{kg}$ and higher in rats were associated with histological changes in the liver which were reversible when the drug was discontinued. In dogs, doses of $20 \mathrm{mg} / \mathrm{kg}$ were also associated with hepatic changes; however, these

changes were reversible with continued dosing

Drug Interaction. Pharmocologic studies indicate that there may be addifive effects in prolonging AV conduction when using beta-blockers or digitalis concomitantly with CARDIZEM. (SEe WARNINGS.)

Controlled and uncontrolled domestic studies suggest that concomitant use of CARDIZEM and beto-blockers or digitalis is usually well tolerated. Available data are not sufficient, however, to predict the effects of concomitont treatment, particularly in patients with left ventricular dystunction or cardiac conduction abnormalities. In healthy volunteers, diltiazem has been shown to increase serum digoxin levels up to $20 \%$

Carcinogenesis, Mutagenesis, Impairment of Fertility. A 24-month study in rats and a 21 -month study in mice showed no evidence of carcinogenicity. There was also no mutogenic response in in vitro bacterial tests. No intrinsic effect on fertility was observed in rats.

Pregnancy. Category C. Reproduction studies have been conducted in mice, rats, and rabbils. Administration of doses ronging from five to ten fimes greater (on o $\mathrm{mg} / \mathrm{kg}$ basis) than the daily recommended therapeutic dose has resulted in embryo and fetal lethality. These doses, in some studies, have been reported to cause skeletal abnormalifies. In the perinatal posinatal studies, there was some reduction in early individual pup weights and survival rates. There was an increased incidence of stillbirths at doses of 20 times the human dose or greater.

There are no well-controlled studies in pregnant women; therefore, use CARDIZEM in pregnant women only if the potential benefit justifies the potential risk to the fetus.

Nursing Mothers. Diltiazem is excreted in human milk. One report suggests that concentrations in breast milk may approximate serum levels. If use of CARDIZEM is deemed essential, an alternative method of infant feeding should be instituted

Pediatric Use. Safety and effectiveness in children hove not been established.

\section{ADVERSE REACTIONS}

Serious adverse reactions have been rare in studies carried out to date, but it should be recognized that patients with impaired ventricular function and cardiac conduction abnormalities have usually been excluded.

In domestic placebo-controlled trials, the incidence of adverse reactions reported during CARDIZEM therapy was not greater than that reported during placebo therapy.

The following represent occurrences observed in clinical studies which can be at least reasonably asso- ciated with the pharmacology of calcium influx inhibitio In many cases, the relationship to CARDIZEM has not been established. The most common occurrences as w as their frequency of presentation are: edema (2.4\%), heodache $(2.1 \%)$, nausea $(1.9 \%)$, dizziness $(1.5 \%)$ rash $(1.3 \%)$, asthenia (1.2\%). In addition, the followir events were reported intrequently (less than 1\%):

Cardiovascular: Angina, amhythmia, AV block (firs degree), AV block (second or thi degree - see conduction warnin bradycardia, congestive heart failure, flushing, hypotension, po tations, syncope

Nervous System: Amnesia, gaif abnormality, halluc notions, insomnia, nervousness, paresthesia, personality change, somnolence, tinnitus, fremor

Gastrointestinal: Anorexia, constipation, diamthea dysgeusia, dyspepsia, mild elevations of alkaline phosphatas SGOT, SGPT, and LDH (see hepat warnings), vomiting, weight increase.

Dermatologic: Petechioe, pruritus, photosensitiv

Amblyopia, dyspnea, epistaxis, imitation, hyperglycemia, nasal congestion, nocturia, ostecorticu pain, polyuria, sexual difficulties.

The following postmarketing events have been reported infrequently in patients receiving CARDIZEM: alopecia, gingival hyperplasia, erythema multiforme, leukopenia. However, a definitive cause and effect between these events and CARDIZEM therapy is yet to $L$ established.

See complete Professional Use Information before prescribing.

References: 1. Pepine WJ, Feldman RL, Hill JA, ef al Clinical outcome after treatment of rest angina with calcium blockers: Comparative experience during the initial year of therapy with diltiazem, nifedipine, and verapamil. Am Heart J 1983; 106(6): 1341-1347. 2. Shapiro W: Calcium channel blockers: Actions on heart and uses in ischemic heart disease. Consultant 1984; 24 (Dec): 150-159. 3. Johnston DL, Lesoway R Humen DP, ef al: Clinical and hemodynamic evaluation propranolol in combination with verapamil, nifedipine and diltiazem in exertional angina pectoris: A placebo controlled, double-blind, randomized, crossover study Am J Cardiol 1985:55:680-687. 4. Cohn PF, Brounw E: Chronic ischemic heart disease, in Braunwald E (ec Heart Disease: A Textbook of Cardiovascular Medicine ed 2 Philadelphio. WB Saunders Co, 1984, chop 39 5. Schroeder JS: Calcium and beta blockers in ischem heart disease: When to use which. Mod Med 1982;50(Sept):94-116. 